\title{
Article \\ Microstructural Evolution and Mechanical Properties of Graphene Oxide-Reinforced Ti6Al4V Matrix Composite Fabricated Using Spark Plasma Sintering
}

\author{
Ying Song ${ }^{1,2}$, Weiwei Liu ${ }^{2}$, Yufeng Sun ${ }^{1,3,4}$, Shaokang Guan ${ }^{1,3,4}$ and Yao Chen ${ }^{1,2,3,4, *}$ \\ 1 School of Materials Science and Engineering, Zhengzhou University, Zhengzhou 450001, China; \\ songying55555@163.com (Y.S.); yfsun@zzu.edu.cn (Y.S.); skguan@zzu.edu.cn (S.G.) \\ 2 School of Mechanical \& Electric Engineering, Soochow University, Suzhou 215006, China; \\ liuweiwei@suda.edu.cn \\ 3 Key Laboratory of Advanced Magnesium Alloys in Henan Province, Zhengzhou 450002, China \\ 4 Key Laboratory of Advanced Materials Processing \& Mold, Ministry of Education of the People's Republic \\ of China, Zhengzhou 450002, China \\ * Correspondence: ychen@zzu.edu.cn; Tel.: +86-512-65790183
}

Citation: Song, Y.; Liu, W.; Sun, Y.; Guan, S.; Chen, Y. Microstructural Evolution and Mechanical Properties of Graphene Oxide-Reinforced Ti6Al4V Matrix Composite Fabricated Using Spark Plasma Sintering. Nanomaterials 2021, 11, 1440. https:// doi.org/10.3390/nano11061440

Academic Editor: Mohammad Jawaid

Received: 30 April 2021

Accepted: 27 May 2021

Published: 29 May 2021

Publisher's Note: MDPI stays neutral with regard to jurisdictional claims in published maps and institutional affiliations.

Copyright: (c) 2021 by the authors. Licensee MDPI, Basel, Switzerland. This article is an open access article distributed under the terms and conditions of the Creative Commons Attribution (CC BY) license (https:/ / creativecommons.org/licenses/by/ $4.0 /)$.

\begin{abstract}
To achieve a further reduction in weight of titanium alloys and to satisfy the increasing demand of energy-saving for aerospace and automotive applications, a graphene oxide nanosheetreinforced Ti6Al4V (GO/TC4) composite was successfully fabricated using spark plasma sintering (SPS). Contrary to the Widmanstätten microstructure of a monolithic TC4 sample, the microstructure of the composites displayed a typical basket-weave structure in virtue of the introduced residual tensile stress generated from the mismatch of coefficients of thermal expansion (CTE) between $\mathrm{GO}$ and TC4 during the phase transformation. Meanwhile, the in situ-formed TiC nanolayer and diffusion layer were identified at the GO-TC4 interface, which is expected to endow a stronger interfacial bonding. As compared with the TC4 sample, the TC4 composite with the addition of $0.27 \mathrm{wt} . \% \mathrm{GO}$ exhibited a $0.2 \%$ yield strength of $921.8 \mathrm{MPa}$, an ultimate tensile strength of $1040.1 \mathrm{MPa}$, and an elongation of $5.3 \%$, displaying a better balance of strength and ductility than that of the composite with a higher $\mathrm{GO}$ addition $(0.54 \mathrm{wt} . \%)$. The synergetic strengthening mechanisms such as Orowan strengthening, enhanced dislocation density strengthening, and load transfer were confirmed. Among them, load transfer contributed greatly to the strength of the composites due to improved interfacial bonding between the GO fillers and TC4 matrix.
\end{abstract}

Keywords: graphene oxide; nanocomposite; titanium matrix; microstructure; mechanical properties; spark plasma sintering

\section{Introduction}

Titanium alloys have been widely recognized as important and promising engineering materials used in diverse industrial fields spanning aerospace, weaponry, automobiles, biomedicine, and others, because they exhibit a good combination of low density [1], high specific strength [2], excellent corrosion resistance [1], and biocompatibility [3]. Among these titanium alloys with different compositions, the Ti6Al4V alloy is dominant in the aerospace market, making up about $60 \%$ of the titanium used in jet engines and up to $80-90 \%$ for airframes $[4,5]$. However, it should be noted that actual applications of the Ti6Al4V alloy in the aerospace and automotive applications are still facing some limitations due to its poor adhesive wear resistance associated with its low hardness and much lower strength than those of high-strength steel [6,7]. Hence, significant efforts have been devoted to develop Ti6Al4V-based composites reinforced by various ceramics such as $\mathrm{TiC}$ [8], $\mathrm{TiB}$ [9], $\mathrm{TiC}-\mathrm{TiB}$ [10], $\mathrm{SiC}$ [11], $\mathrm{ZrO}_{2}$ [12], and $\mathrm{Ti}_{5} \mathrm{Si}_{3}$ [13], in which TiB whisker and $\mathrm{TiC}$ particles have been well demonstrated to be the optimal reinforcements due to the fact that they not only exhibit a high modulus and hardness, but also possess similar densities 
and coefficients of thermal expansion (CTE) to Ti6Al4V alloy, subsequently contributing to the reduction in residual stresses at the interface of the designed composites $[14,15]$. For example, Huang et al. [15] successfully fabricated tailor-designed titanium matrix composites with the reticular reinforcement architecture of $\mathrm{TiC}_{\mathrm{p}}$ or $\mathrm{TiB}$, imparting the composites with an enhanced strengthening effect in a wide range of temperatures.

For a further reduction in weight of titanium alloys to satisfy the increasing demand of energy-saving in aerospace and automotive applications, it is imperative to develop titanium-based composites reinforced by novel reinforcing agents with a higher strength and lower density compared to those of the conventional ceramics. Graphene is a twodimensional nanomaterial comprising a single-layer of $\mathrm{sp}^{2}$-hybridized carbon atoms and exhibits excellent mechanical and physical properties, including a high tensile strength $(\sim 130 \mathrm{GPa})$, high Young's modulus ( 1.0 TPa), large surface area $\left(\sim 2630 \mathrm{~m}^{2} / \mathrm{g}\right)$, and very low density $\left(\sim 1.8 \mathrm{~g} / \mathrm{cm}^{3}\right)$ [16-18], making it more suitable as a reinforcing nanofiller to improve the mechanical properties of metal materials [19]. As compared to the well-known one-dimensional carbon nanotube (CNT), selecting graphene as a reinforcement has the following advantages: (1) graphene is much more cost-effective than CNT and can be produced on a large scale; (2) graphene with a higher surface area is prone to form stronger interfacial bonding with a metal matrix.

It should be noted, however, that the great challenge in graphene-reinforced metallic composites is to tailor the homogeneous distribution of these 2D nanofillers in the matrix in a suitable manner, because the strong van der Waals force between the multilayer graphene (MLG) usually forms graphene clusters, subsequently leading to stress concentration, acting as crack nuclei [7]. To this end, the current powder mixing methods applied in the graphene-reinforced metal composites are usually ball milling [20,21] and/or ultrasonic dispersion $[22,23]$ because of their simplicity, time demands, and cost efficiency. Nevertheless, a high impact force and shear force along with ball milling, especially with high-energy ball milling (HEBM), have been reported to reduce the graphene size and to destroy its structural integrity, which is believed to easily introduce defects and impurities in the original graphene structure [24,25]. As such, the improvement in mechanical properties of graphene-reinforced metal matrix composites usually fails to achieve the level of graphene/polymer composites.

As an important derivative of graphene, graphene oxide (GO) with reactive groups populating its edge (carbonyl and carboxyl groups) and planes (hydroxyl and epoxide groups) has been demonstrated to possess desirable dispersion behavior in aqueous media [26]. Moreover, GO possesses good mechanical properties [27] and is easier to produce on a large scale than graphene is. Such typical characteristics associated with GO hold great promise for serving as nanofillers in the development of high-performance metallic composites. Although some investigations have been conducted on the GO-reinforced pure titanium composites, little information focusing on the efficacy of the GO on the microstructure evolution and mechanical properties of Ti6Al4V composites is available. Herein, the aim of the present work, as an extension of our previous investigation [28], was to reveal the influence of GO on the matrix microstructure, interfacial structure, and mechanical properties of Ti6Al4V-based composites fabricated using spark plasma sintering (SPS), which is beneficial for their practical industrial applications.

\section{Materials and Methods}

Argon atomized pre-alloyed Ti6Al4V (hereafter referred to as TC4) powders (Falcon Technology Co., Ltd., Wuxi, China) with an average size of $\sim 15-60 \mu \mathrm{m}$ were used as precursor material in this research. The morphology of the TC4 powders was observed by scanning electron microscopy (SEM, Hitachi S-4700, Tokyo, Japan), as depicted in Figure 1a. GO agglomerated powders (purity: 99.9\%) with a thickness of $\sim 0.55-1.2 \mathrm{~nm}$ (Chengdu Organic Chemicals Co. Ltd., Chengdu, China) were used as the reinforcing nanofillers, as shown in Figure 1b. 

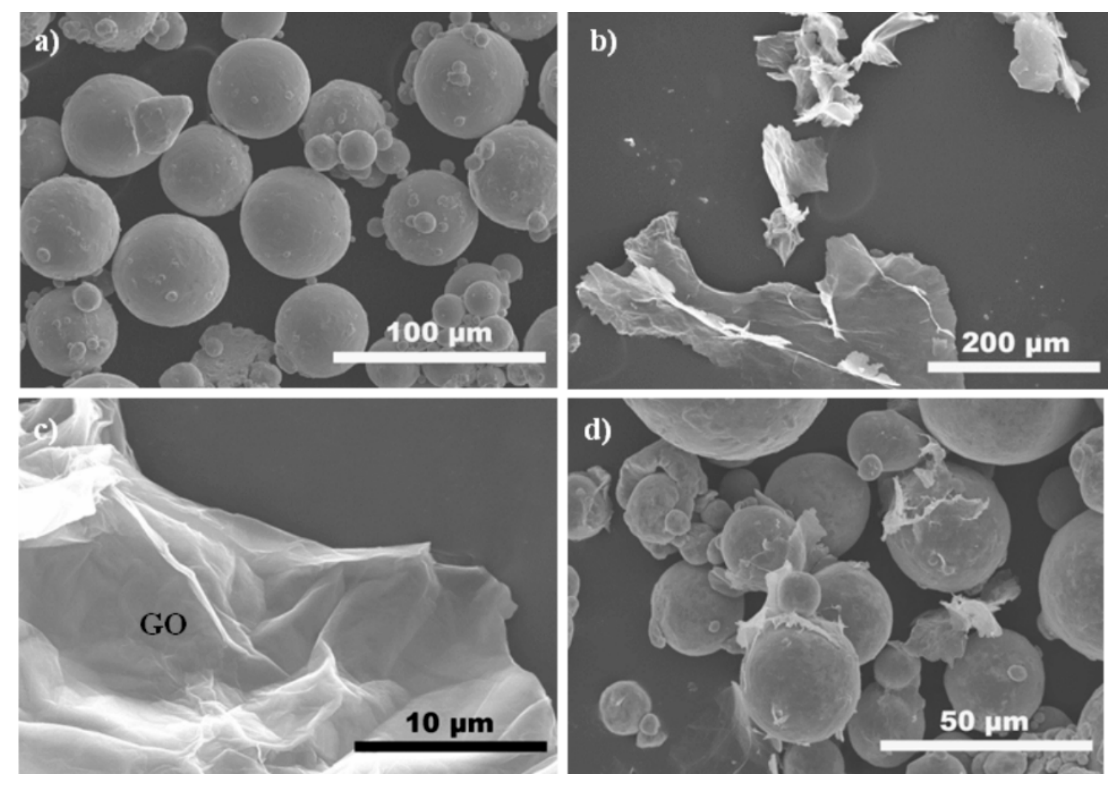

Figure 1. SEM images of the as-received TC4 powders (a), GO powders (b), GO nanosheet after ultrasonication (c), and GO-TC4 composite powders (d).

The electrostatic self-assembly method was employed to homogeneously disperse GO in the TC4 powders, in which the GO dispersion solution with a negative charge is expected to uniformly adhere to the surface of the TC4 powder with a positive charge, functionalized through the addition of cetyltrimethyl ammonium bromide (CTAB). GO agglomerates $(0.65 \mathrm{~g})$ were added into deionized water $(250 \mathrm{~mL})$ for $30 \mathrm{~min}$ of ultrasonication, which was subjected to zeta-potential measurement (Zetasizer Nano ZS90 DLS, Malvern, UK). The zeta potential of the GO solution was $-21.6 \mathrm{mV}$. It should be noted that the GO powders were all heated to $120^{\circ} \mathrm{C}$ under vacuum conditions prior to the preparation of GO suspension. Figure $1 \mathrm{c}$ shows the GO nanosheet after ultrasonication, and it was found that as-received GO agglomerates were effectively exfoliated to several layers, and its rough and wrinkled surface was also noticeable. On the other hand, CTAB was added into deionized water to obtain a $0.1 \mathrm{wt} . \% \mathrm{CTAB}$ aqueous solution, and it was stirred at $50{ }^{\circ} \mathrm{C}$ until the solution became transparent. Afterward, TC4 powders $(130 \mathrm{~g})$ were added into the CTAB aqueous solution $(130 \mathrm{~mL})$ followed by ultrasonication for $10 \mathrm{~min}$. The CTAB-TC4 slurry was centrifuged by refrigerated centrifuge (Allegra X-15R, Beckman Coulter, Pasadena, CA, USA) for $20 \mathrm{~min}$ at $3000 \mathrm{r} / \mathrm{min}$, and it was then washed twice with deionized water. The zeta potential of the CTAB-functionalized TC4 suspension was measured to be $38.6 \mathrm{mV}$. Finally, the CTAB-TC4 suspension and GO dispersion were fully mixed through magnetic stirring. Stationary standing of the mixed slurry was employed until the color became transparent. The mixed slurry was filtered and rinsed, followed by vacuum drying at $100^{\circ} \mathrm{C}$ for $8 \mathrm{~h}$ to obtain the composite powders. Figure $1 \mathrm{~d}$ shows an SEM micrograph of the as-prepared powder mixture where the platelet-like GO adhered to the surface of these TC4 spherical particles in virtue of the electrostatic self-assembly process. For comparison, TC4, $0.5 \mathrm{wt} . \%$ GO-TC4, and $1.0 \mathrm{wt} . \%$ GO-TC4 composite powders were employed in this research.

A spark plasma sintering (SPS) system (LABOX-330, SINTER LAND, Niagata, Japan) was used to fabricate monolithic TC4 samples with and without GO addition. The GO-TC4 powder mixture was compacted at $1100{ }^{\circ} \mathrm{C}$ under a pressure of $30 \mathrm{MPa}$ in a graphite die (inner diameter: $30 \mathrm{~mm}$, height: $40 \mathrm{~mm}$ ). A heating rate of $50^{\circ} \mathrm{C} / \mathrm{min}$ was used for raising the fabrication temperature up to $1100{ }^{\circ} \mathrm{C}$, followed by an isothermal holding time of $30 \mathrm{~min}$. The samples were then cooled down to ambient temperature with a cooling rate of the furnace. It should be noted that graphite papers were placed between the powders and 
die/punches for easy specimen removal. For comparison, the monolithic TC4 sample was fabricated following the same processing.

Phase identification of the sintered samples was carried out through X-ray diffraction (XRD, X'Pert-ProMRD, Almelo, Holland) with $\mathrm{Cu} \mathrm{K} \alpha$ radiation using a scanning rate of $20^{\circ} / \mathrm{min}$ at a range of 20 to $90^{\circ}$. Metallographic samples were prepared using standard procedures and etched with a solution consisting of $7 \mathrm{~mL}$ of $\mathrm{H}_{2} \mathrm{O}, 2 \mathrm{~mL}$ of $\mathrm{HF}$, and $1 \mathrm{~mL}$ of $\mathrm{HNO}_{3}$. Microstructure observations of the sintered samples were carefully examined using optical microscopy (OM, 4XB, Shanghai Taiming Optical Instrument Co., Ltd., Shanghai, China), SEM, and high-resolution transmission electron microscopy (HRTEM, Tecnai 20 G2, FEI The Netherlands). The relative densities of SPS-fabricated samples were determined based on the Archimedes principles, and each sample was measured at least five times to achieve repeatability. The thermal stability of $\mathrm{GO}$ was measured using a thermal gravimetric analyzer (TGA, Pyris-1, PE, USA) in the temperature range of $25-800{ }^{\circ} \mathrm{C}$ with a heating rate of $10{ }^{\circ} \mathrm{C}$. Fourier-transform infrared (FT-IR) of the as-received GO and SPSed composites was performed using a VERTEX 70+HYPERION 2000 apparatus (Bruker, Karsruhe, Germany).

Tensile specimens with a cross-section of $2.0 \times 1.0 \mathrm{~mm}$ and a gauge length of $15 \mathrm{~mm}$ were machined by wire electric discharge machining from the as-sintered sample. Tensile tests were conducted on each sample under a constant cross-head speed with an initial strain rate of $1 \times 10^{-3} / \mathrm{s}$ using an Instron 5566 testing machine.

\section{Results and Discussion}

\subsection{Microstructure Characteraziation of the Composites}

The thermal stability of as-received GO measured using TGA is shown in Figure 2a, and it demonstrates that GO first experienced a slight mass reduction $(\sim 12 \%)$ when it was heated up to $\sim 120^{\circ} \mathrm{C}$, which should be closely related to water loss. In the second stage $\left(120^{\circ} \mathrm{C}-250{ }^{\circ} \mathrm{C}\right)$, there was a significant mass loss ( 28\%) of GO, corresponding to decomposition of the oxygen-containing groups (hydroxyl and carboxyl) [25]. Finally, a further mass loss ( 18\%) of GO occurred due to the fact that epoxy groups along with GO started to decompose at $270{ }^{\circ} \mathrm{C}$. As stated before, the as-received GO powders were preserved at $120^{\circ} \mathrm{C}$ under vacuum conditions prior to preparation of the GO suspension. Therefore, it is reasonable that the actual content of the added GO retained in the SPSed composites was only $\sim 54 \%$ as compared to that in the as-prepared composite powders, i.e., the weight fractions of the addition of GO in the composites were $0.27 \mathrm{wt} . \%$ for 0.5 wt. $\%$ GO/TC4 composite powders and $0.54 \mathrm{wt} . \%$ for $1.0 \mathrm{wt} . \% \mathrm{GO} / \mathrm{TC} 4$ composite powders (hereafter represented as $0.27 \mathrm{GO} / \mathrm{TC} 4$ and $0.54 \mathrm{GO} / \mathrm{TC} 4$, respectively).

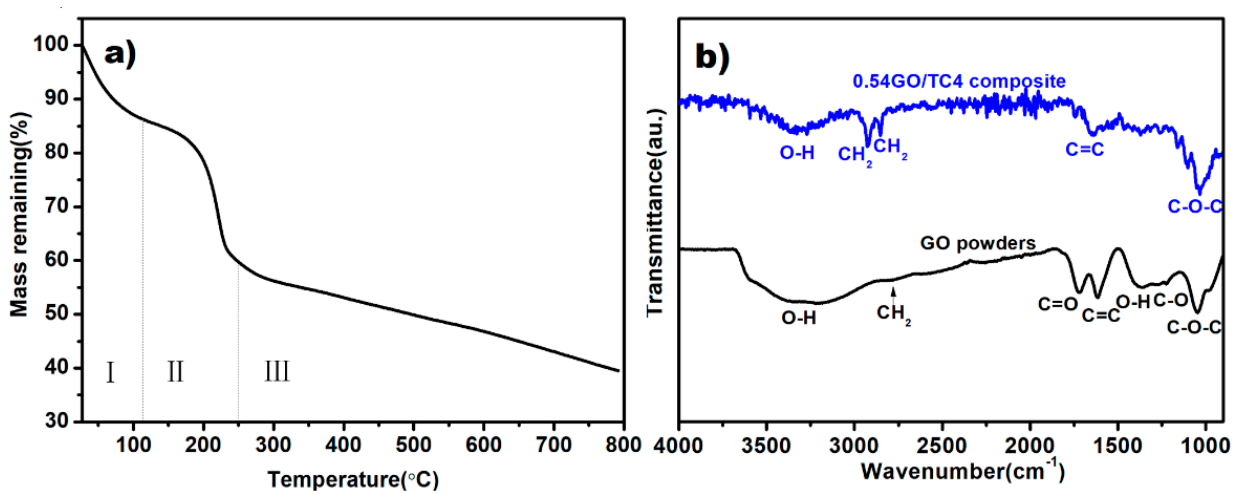

Figure 2. (a) TGA plot of the as-received GO powders, and (b) FT-IR spectra of as-received GO powders and as-sintered GO/TC4 composites.

FT-IR spectra of the as-received GO and SPSed composite are depicted in Figure 2b. As for the as-received GO powders, the peak observed at a wavenumber of $1049 \mathrm{~cm}^{-1}$ is related to the stretching vibration of the C-O-C band, and the signal at $1213 \mathrm{~cm}^{-1}$ is 
assigned to the stretching vibration of the $\mathrm{C}-\mathrm{O}$ bond in epoxy groups. The peak that appeared at $1729 \mathrm{~cm}^{-1}$ should correspond to the $\mathrm{C}=\mathrm{O}$ band in the carboxyl and carbonyl groups, and the broad peak between 3100 and $3700 \mathrm{~cm}^{-1}$ is due to the stretching vibration of the O-H bond from hydroxyl groups and/or water molecules. Additionally, the peak at $1619 \mathrm{~cm}^{-1}$ ascribes to the stretching vibration of the $\mathrm{C}=\mathrm{C}$ band. In contrast, the adsorptions of $\mathrm{C}-\mathrm{H}, \mathrm{O}-\mathrm{H}$, and $\mathrm{C}-\mathrm{O}$ bonds that appeared in the FT-IR spectrum of the sintered GO/TC4 composite were significantly weaker than those of as-received GO powders. Hence, the TGA and FI-TR results sufficiently demonstrate that the addition of GO was partially reduced to rGO in the SPS process.

As shown in Figure 3a, it is clear that the sintered TC4 sample displayed a typical Widmanstätten microstructure, in which several colonies consisting of alternate layers of the $\alpha$ phase and thin secondary $\beta$ phase were randomly oriented in the primary $\beta$ phase. It is also interesting to observe that the primary $\beta$ grains grew rapidly in such a way that their size was significantly larger than that of the as-received TC4 powders $(15-60 \mu \mathrm{m})$, which is likely due to the fact that several as-received TC4 powders were consolidated through high pressure along with the SPS process and new primary $\beta$ phase developed from the merged $\beta$ phase. In striking contrast, the microstructure of the sintered composites developed into $\alpha$ laths and an intergranular $\beta$ phase, in which the $\alpha$ laths intersected each other to form a typical basket-weave structure (Figure $3 b, c)$. Hence, the comparison of the microstructure leaves no doubt that the addition of GO nanosheets is capable of influencing the matrix microstructure of the sintered composites.
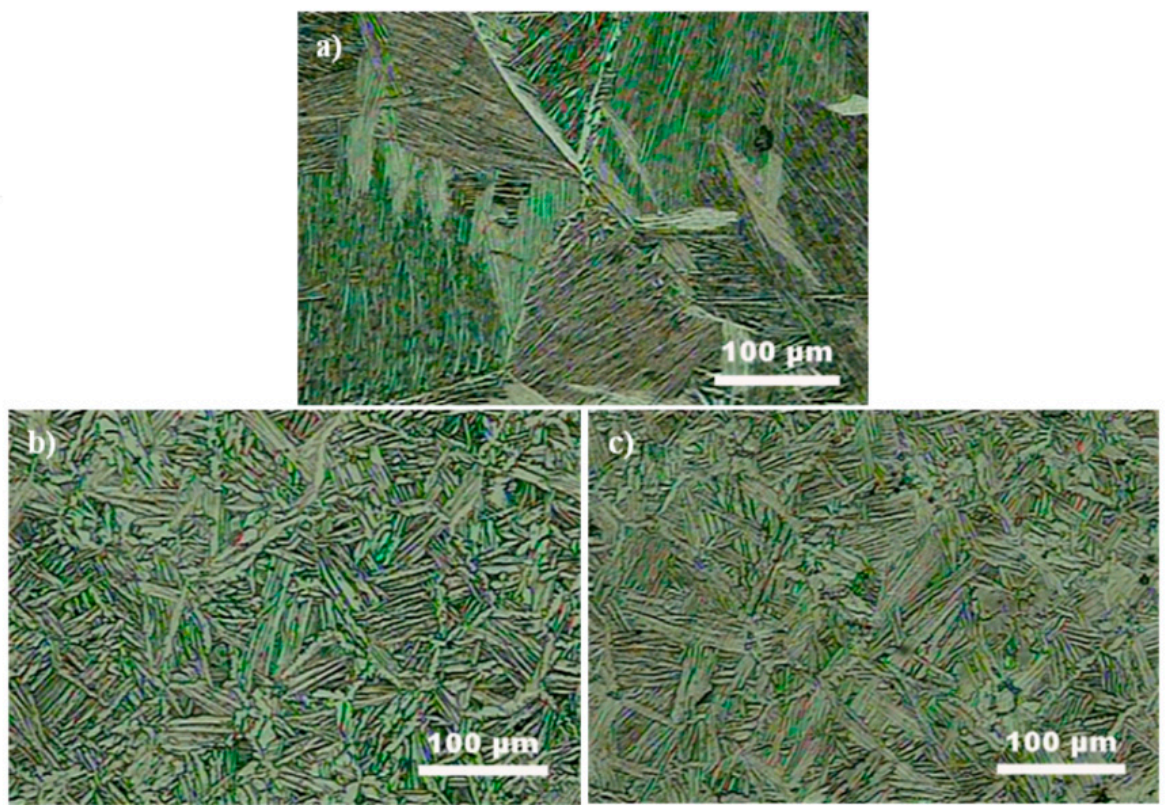

Figure 3. OM images showing typical microstructure of the monolithic TC4 sample (a), 0.27GO/TC4 composite (b), and 0.54GO/TC4 composite (c).

As for the $\alpha+\beta$ two-phase titanium alloys, it is well known that the Widmanstätten microstructure is significantly controlled by elastic strain energy generated from the different specific volumes of the new phase and parent phase during phase transformation [29], i.e., lower elastic strain energy often allows for a Widmanstätten microstructure in the process of slow cooling from above the $\beta$ transus temperature $\left(\sim 990^{\circ} \mathrm{C}\right)$ associated with SPS parameters employed in this research. In the composites, it should be pointed out that GO exhibits a much smaller value $\left(-8.0 \times 10^{-6} \mathrm{~K}^{-1}\right)$ [27] of the coefficient of thermal expansion (CTE) than that of TC4 alloy $\left(9.5 \times 10^{-6} \mathrm{~K}^{-1}\right)$ [30], which would produce a high residual tensile stress within the Ti matrix in the vicinity of these nanofillers. Thus, the residual tensile stress is believed to generate a higher elastic strain energy of the ma- 
trix, subsequently warding off the formation of a Widmansätten microstructure in the composite.

XRD patterns of SPSed samples are depicted in Figure $4 \mathrm{a}$, and it is clear that the addition of GO had no effect on the phase constituents of the sintered samples, i.e., all the sintered samples consisted of an $\alpha$ phase and $\beta$ phase. Figure $4 \mathrm{~b}$ shows the Raman spectra of the as-received GO powders and sintered composites. As compared with the main features ( $D$ and $G$ peaks) presented in the Raman spectra, it is visible that the value of $\mathrm{I}_{\mathrm{D}} / \mathrm{I}_{\mathrm{G}}$ decreased from $\sim 1.02$ (GO powders) to $\sim 0.82$ (composites). Due to the fact that the attachment of hydroxyl and epoxide groups on the carbon basal plane usually causes the prominent $D$ peak [31], the remarkable decrease in the values of $I_{D} / I_{G}$ associated with the sintered composites is believed to provide more evidence that functional groups of the GO powders fully or partially released during spark plasma sintering.
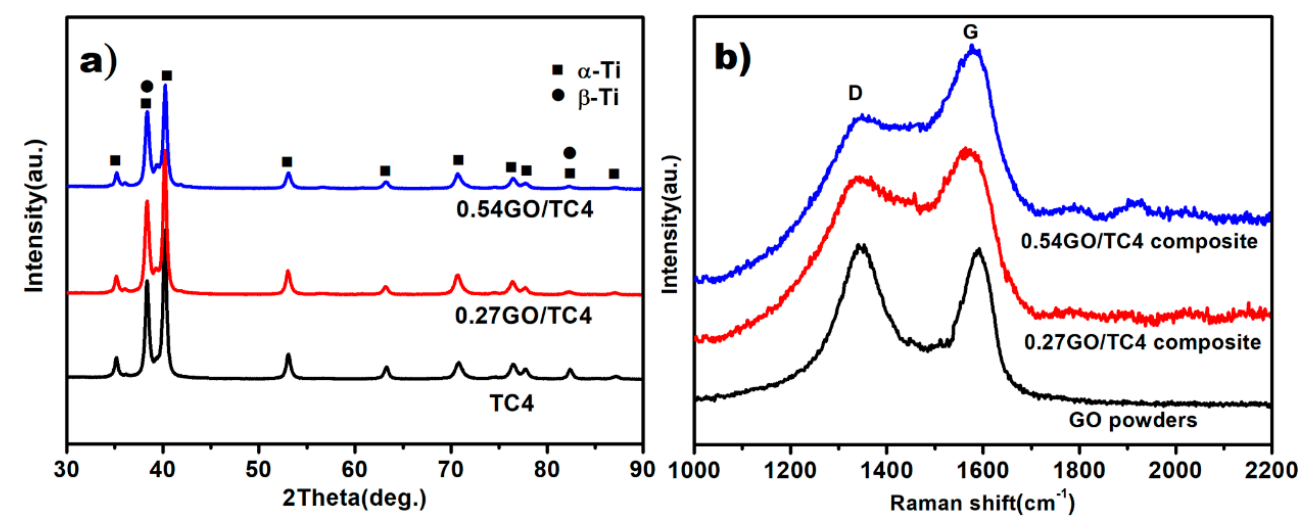

Figure 4. (a) XRD results of sintered samples, and (b) Raman spectra of as-received GO powders and sintered TC4 composites.

The interfacial structure between the reinforcement and the matrix plays a remarkable role in the mechanical properties of metal matrix composites [19]. Figure 5a shows the typical interfacial structure of the GO/TC4 composite. The presence of both GO and $\alpha$-Ti was confirmed by the HRTEM images in Figure $5 b, c$, which is represented by the white square regions labeled $b 1$ and $b 2$, respectively. The measured lattice spacings of GO and $\alpha$-Ti were $\sim 0.34$ and $\sim 0.215 \mathrm{~nm}$, corresponding to the (0002) crystal plane of graphene and (002) crystal plane of $\alpha-\mathrm{Ti}$, respectively. As noted in Figure 5d, the HRTEM image of the white square region labeled as b3 in Figure 5a, the localized interfacial product of the $\mathrm{TiC}$ nanolayer, revealed by the lattice spacing of $0.23 \mathrm{~nm}$ of the (200) crystal plane of $\mathrm{TiC}$, was confirmed to form adjacent to the open edge of the GO nanosheet, sufficiently illustrating that open edges of GO are more reactive than its basal planes are and facilitate preferential nucleation and growth of $\mathrm{TiC}$. In addition to the local interfacial reaction zone, it is evident from Figure 5e, the HRTEM image of zone b4 in Figure 5a, that a disordered layer with a width of $\sim 1-2 \mathrm{~nm}$ was visible, and that this layer blurred the interface between GO and $\alpha$-Ti, strongly implying that mutual diffusion of carbon and titanium atoms might be responsible for this layer. 

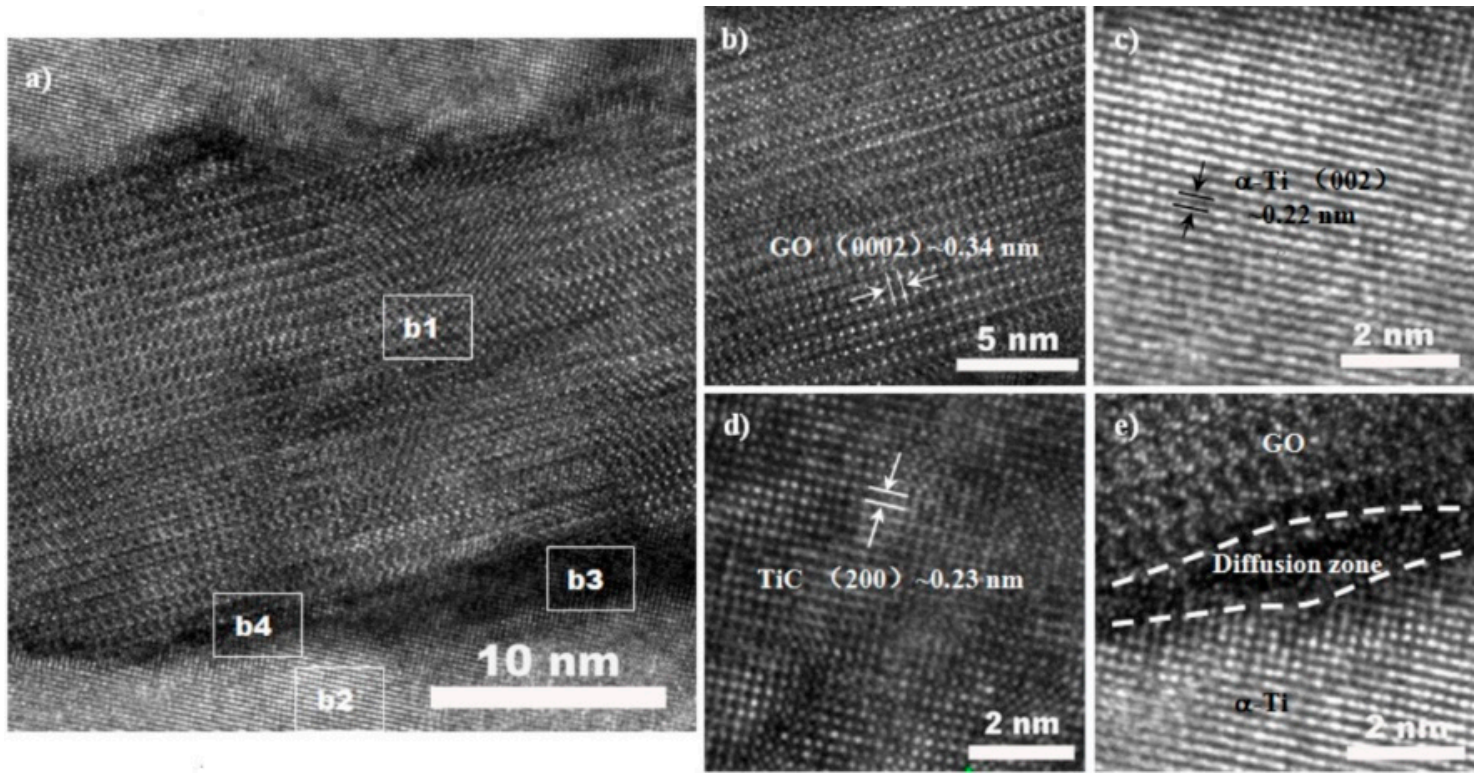

Figure 5. HRTEM images showing (a) detailed GO-TC4 interfacial structure, (b) the remaining GO located near the Ti matrix (the white square region b1 in (a)), (c) the corresponding lattice spacing of $\alpha$-Ti and its SAED at the marked region of b2, (d) in situ-formed TiC nanolayer (the white square region b3 in (a)), and (e) the diffusion layer (the white square region b4 in (a)).

\subsection{Mechanical Properties of the Composites}

The measured densities of the sintered samples were $4.362 \pm 0.010,4.356 \pm 0.012$, and $4.343 \pm 0.012 \mathrm{~g} / \mathrm{cm}^{3}$ for the pure TC4 sample, $0.27 \mathrm{GO} / \mathrm{TC} 4$ sample, and $0.54 \mathrm{GO} / \mathrm{TC} 4$ sample, respectively. On the basis of the theoretical densities of TC4 $\left(\sim 4.40 \mathrm{~g} / \mathrm{cm}^{3}\right)$ [32] and GO $\left(\sim 2.26 \mathrm{~g} / \mathrm{cm}^{3}\right)$ [27], it is obvious that the theoretical densities of $0.27 \mathrm{GO} / \mathrm{TiC} 4$ and $0.54 \mathrm{GO} / \mathrm{TC} 4$ composites were 4.394 and $4.389 \mathrm{~g} / \mathrm{cm}^{3}$, respectively. Hence, the relative densities of the TC4 sample, and $0.27 \mathrm{GO} / \mathrm{TC} 4$ and $0.54 \mathrm{GO} / \mathrm{TC} 4$ composites were $\sim 99.1 \%$, $\sim 99.1 \%$, and $\sim 99.0 \%$, respectively. The imperceptible differences in the relative density of the sintered samples imply that these added GO nanosheets distributed homogeneously in the TC4 matrix.

Figure 6 shows the tensile stress-strain curves of SPSed TC4 samples, and the tensile properties of these samples interpreted from the engineering stress-engineering strain curves are listed in Table 1. As shown, the TC4 sample exhibited an elastic modulus of $\sim 110.5 \mathrm{MPa}$, a $0.2 \%$ yield strength (YS) of $\sim 790.7 \mathrm{MPa}$, and an ultimate tensile strength (UTS) of $\sim 855.7 \mathrm{MPa}$. The GO strengthening effects varied with its addition content, which was more significant at an addition content of $0.54 \mathrm{wt} . \%$, exhibiting an elastic modulus of $\sim 133.3 \mathrm{MPa}$, yield strength of $\sim 1044.2 \mathrm{MPa}$, and ultimate tensile strength (UTS) of $\sim 1053.4 \mathrm{MPa}$, which were enhanced by $\sim 22 \%, \sim 32 \%$, and $\sim 23 \%$, respectively, compared with those of the monolithic TC4 sample composite. Nevertheless, it is necessary to point out that the improved strength associated with the addition of GO in the composites was achieved by compromising their elongation to failure, especially for the $0.54 \mathrm{GO} / \mathrm{TC} 4$ sample, sharply decreasing to $\sim 1.8 \%$ with respect to the TC4 sample $(\sim 6.8 \%)$. As compared to the results reported in previous investigations, the $0.25 \mathrm{wt} . \%$ graphene/TC4 composite fabricated using SPS at high pressures (250 MPa) displayed a YS of $~ 964 \mathrm{MPa}$ and UTS of $\sim 999 \mathrm{MPa}$, but its elongation to failure was only $\sim 0.9 \%$ [7]; Dong et al. reported that the SPSed $0.15 \mathrm{wt} . \%$ GO/TC4 composite possessed a lower YS ( 897 MPa) and UTS ( $951 \mathrm{MPa})$ with a similar elongation to failure $(\sim 5.4 \%)$ [33]. Hence, it is reasonable that, in the case of graphene and/or graphene oxide-reinforced TC4 composites fabricated using SPS without post-treatments such as hot rolling and hot extrusion, the $0.27 \mathrm{GO} / \mathrm{TC} 4$ composite in this research (YS of $\sim 921.8 \mathrm{MPa}$, UTS of $\sim 1040.1 \mathrm{MPa}$, and elongation to failure of $\sim 5.3 \%$, as 
listed in Table 1) exhibited the combination of higher YS and UTS without much sacrifice of ductility, achieving a better balance between strength and ductility.

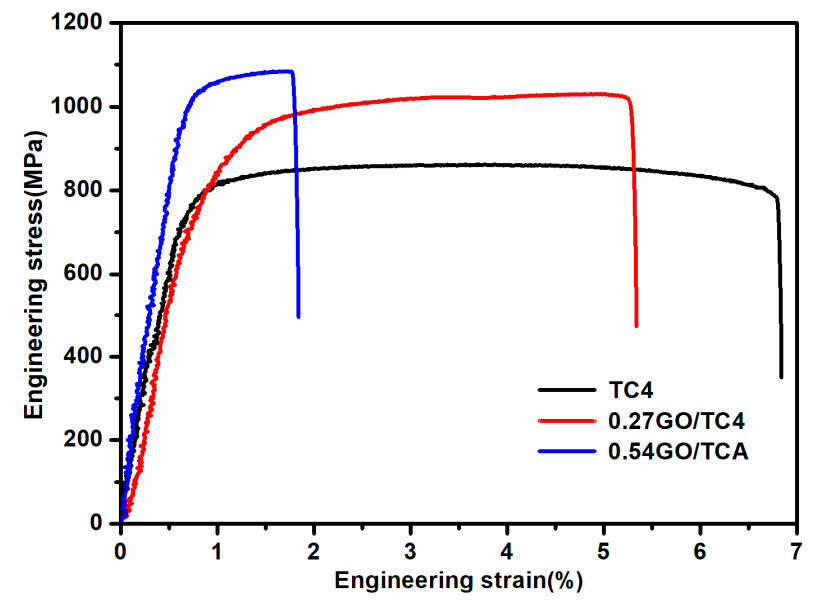

Figure 6. Tensile stress-strain curves of the sintered samples with different contents of GO nanosheets.

Table 1. Mechanical properties of SPSed TC4 and GO/TC4 composites.

\begin{tabular}{ccccc}
\hline Samples & $\boldsymbol{E} \mathbf{( G P a )}$ & YS $\mathbf{( M P a )}$ & UTS (MPa) & $\varepsilon$ (\%) \\
\hline TC4 & $110.5 \pm 5.4$ & $790.7 \pm 3.3$ & $855.7 \pm 15.6$ & $6.8 \pm 0.7$ \\
$0.27 \mathrm{GO} / \mathrm{TC} 4$ & $123.4 \pm 3.7$ & $921.8 \pm 5.3$ & $1040.1 \pm 8.5$ & $5.3 \pm 0.6$ \\
$0.54 \mathrm{GO} / \mathrm{TC} 4$ & $133.3 \pm 3.2$ & $1034 \pm 4.5$ & $1053.4 \pm 27.4$ & $1.8 \pm 0.5$ \\
\hline
\end{tabular}

As indicated in Table 2, it is believed that the addition of GO exerted a significant strengthening role in the TC4 composites. To understand the strengthening mechanisms of GO/TC4 composites, the following aspects should be focused: (1) Orowan strengthening of the added GO, (2) enhanced dislocation density (EDD) strengthening by mismatch in coefficient of thermal expansion (CTE) between GO and TC4, (3) load transfer from TC4 matrix to GO, (4) grain refinement pinned by GO, and (5) solid solution strengthening by carbon atoms diffused into TC4 matrix. Among these strengthening mechanisms, solid solution strengthening induced by interstitial carbon atom diffusion into the TC4 matrix can be negligible due to the fact that the further addition of carbon in titanium alloys has little effect on the improved strength when the carbon concentration is beyond its limit ( $0.05 \mathrm{wt} . \%$ for $\alpha$-Ti at ambient temperature) [34]; in addition, the addition of GO led to a remarkable difference in the microstructure (Figure 3), i.e., with the formation of a basketweave microstructure in the composite matrix other than the Widmansätten microstructure presented in the monolithic TC4 sample, it is unsuitable to make a quantitative estimation of grain refinement on the enhanced strength of the composite samples, and therefore, the grain refinement was also ignored in this research.

Table 2. Strengthening contributions of GO/TC4 composites (MPa).

\begin{tabular}{ccccccc}
\hline Sample & $\Delta \sigma_{\text {orowan }}$ & $\Delta \sigma_{\text {EDD }}$ & $\Delta \sigma_{L T}$ & $\Delta \sigma_{\text {cal }}$ & $\Delta \sigma_{\text {exp }}$ & $\Delta \sigma_{\text {cal-exp }}$ \\
\hline $0.27 \mathrm{GO} / \mathrm{TC} 4$ & 2.7 & 15.6 & 117.7 & 136.0 & 131.1 & 4.9 \\
$0.54 \mathrm{GO} / \mathrm{TiC} 4$ & 3.7 & 21.9 & 235.3 & 260.9 & 243.3 & 17.6 \\
\hline
\end{tabular}

where $\Delta \sigma_{\text {cal }}$ is the total calculated strengthening contribution, and $\Delta \sigma_{\exp }$ is the increment in experimental yield strength of the composites as compared with that of the monolithic TC4 sample.

Load transfer has been demonstrated to be a very important strengthening mechanism in the case of carbonaceous nanomaterial-reinforced metal composites, in which the load upon the matrix should be efficiently transferred to the reinforcing nanofillers through the interfacial shear action. As such, these nanofillers with outstanding mechanical properties 
are expected to bear a great portion of loading. The shear-lag model is commonly employed to estimate the load transfer strengthening efficacy in the composites, and the enhancement of the yield strength of composites $\left(\Delta \sigma_{L T}\right)$ can be expressed as follows [35]:

$$
\begin{gathered}
\text { for } l<l_{c} \\
\Delta \sigma_{L T}=\sigma_{G O} V_{f} \frac{l}{2 l_{c}}-\sigma_{m} V_{f} \\
\text { for } l>l_{c} \\
\Delta \sigma_{L T}=\sigma_{G O} V_{f}\left(1-\frac{l_{c}}{2 l}\right)-\sigma_{m} V_{f}
\end{gathered}
$$

where $\sigma_{G O}$ is the yield strength of GO (24.7 GPa) [36], $\sigma_{m}$ is the matrix yield strength (790.7 MPa of the monolithic TC4 sample measured in this research), and $V_{f}$ is the volume fraction of GO in the composite (0.52 vol.\% for $0.27 \mathrm{GO} / \mathrm{TC} 4$ sample and $1.04 \mathrm{vol} . \%$ for $0.54 \mathrm{GO} / \mathrm{TC} 4$ sample, respectively). $l_{c}$ is the critical length defined as [37]:

$$
l_{c}=\sigma_{G O} \frac{A l}{\tau_{m} S}
$$

where $\tau_{m}$ is the shear strength of titanium matrix $\left(\approx 0.5 \sigma_{m}\right)$, and A and S are the crosssectional area and interfacial area of GO, respectively, assuming that $A=w t$ and $S=2(w+t) l[36]$, in which $w, t$, and $l$ are the width, thickness, and length of GO, respectively. In the calculation, $l=\sim 3 \mu \mathrm{m}, w=\sim 3 \mu \mathrm{m}$, and $t=\sim 0.01 \mu \mathrm{m}$ were employed. Hence, the calculated $l_{c}$ was $0.31 \mu \mathrm{m}$. As such, based on Equation (2), $\Delta \sigma_{L T}$ can be calculated to be $\sim 117.7$ and $\sim 235.3 \mathrm{MPa}$ for $0.27 \mathrm{GO} / \mathrm{TC} 4$ and $0.54 \mathrm{GO} / \mathrm{TC} 4$ composites, respectively.

In the case of GO-reinforced metal composites, these added GO nanosheets can act as obstacles to hinder dislocation movement (back stress), and the improved yield strength $\left(\Delta \sigma_{\text {Orowan }}\right)$ induced by the Orowan mechanism can be calculated using [37]

$$
\Delta \sigma_{\text {orowan }}=0.13 G b \frac{\ln \left(d_{p} / 2 b\right)}{d_{p}\left[\left(1 / 2 V_{f}\right)^{1 / 3}-1\right]}
$$

where $G$ is the shear modulus of the matrix (24.7 GPa) [30], $b$ is the Burgers vector of TC4 $(0.24 \mathrm{~nm})$ [30], and $d_{p}$ is the reinforcement particle diameter obtained by assuming a spherical model:

$$
d_{p}=\sqrt[3]{\frac{6 w t l}{\pi}}
$$

The estimated $d_{p}(\mathrm{GO})$ was $\sim 0.56 \mu \mathrm{m}$, and the calculated $\Delta \sigma_{\text {Orowan }}$ for the $0.27 \mathrm{GO} / \mathrm{TC} 4$ and $0.54 \mathrm{GO} / \mathrm{TC} 4$ composites were $\sim 2.7$ and $\sim 3.7 \mathrm{MPa}$, respectively.

A significant mismatch in CTE between the reinforcement and matrix usually induces an enhanced dislocation density within the matrix adjacent to the interface, subsequently leading to strengthening. The strengthening effect can be expressed as the following equations [38]:

$$
\Delta \sigma_{E D D}=\kappa G b \rho^{1 / 2}
$$

in which $\kappa$ is the geometric constant (1.25) [27], and the density of dislocation is calculated by [39]

$$
\rho=\frac{B V_{f} \mathcal{E}}{b\left(1-V_{f}\right)} \frac{1}{d_{p}}
$$

where $B$ is 8 for the platelet, and $\varepsilon$ is expressed as [39]

$$
\varepsilon=\Delta \alpha \times \Delta T
$$

where $\Delta \alpha$ is the difference between the coefficients of thermal expansion of the TC4 matrix $\left(9.5 \times 10^{-6} \mathrm{~K}^{-1}\right)$ [30] and $\mathrm{rGO}\left(-8.0 \times 10^{-6} \mathrm{~K}^{-1}\right)$ [27], and $\Delta T$ is the difference between the sintering and test temperatures $(1075 \mathrm{~K})$. Therefore, the calculated $\Delta_{\sigma E D D}$ were 15.6 and 21.9 MPa for 0.27GO/TC4 and 0.54GO/TC4 composites, respectively. 
The calculated strengthening contributions of $\Delta \sigma_{\text {orowan }}, \Delta \sigma_{E D D}$, and $\Delta \sigma_{L T}$ are summarized in Table 2. It is well known that Orowan strengthening usually exhibits little improvement in the microsized particle-reinforced metal matrix composite due to the fact that these reinforcement particles are coarse and the inter-particle spacing is large. In this research, the lateral size of these embedded GO was up to several micrometers, which was likely ascribed to a negligible Orowan-strengthening contribution (2.7-3.7 $\mathrm{MPa})$ to the composite. In contrast, EDD strengthening and load transfer were of significant importance in the TC4 composites. In particular, load transfer was greatly dominant for the enhanced yield strength (118-253 MPa) of the SPSed composites. As discussed above, these defects presented on the GO edges are capable of providing active sites for the in situ formation of a local TiC nanolayer, subsequently imparting improved interfacial bonding with the GO-TC4 interface. In addition, a diffusion layer (as depicted in Figure 5e) would also lead to a coherent interface. Hence, it is reasonable that such interfacial characteristics, along with the added GO with a large contact area with the TC4 matrix, should be greatly responsible for the improved strength of the composites.

The tensile fractured surfaces of the SPSed samples were characterized using SEM, as depicted in Figure 7. As is illustrated in Figure 7a, numerous larger dimples were visible for the pure TC4 sample, indicating that it underwent a ductile fracture mode. In the case of the $0.27 \mathrm{GO} / \mathrm{TC} 4$ composite, its fracture surface was covered with more reduced dimples (Figure 7b). Furthermore, with a further increase in GO content to $0.54 \mathrm{wt} . \%$, the dimple feature gradually disappeared, and brittle fracture occurred in terms of cleavage-like failure and intergranular fracture (Figure 7c). Moreover, the presence of the micropores on the fracture surface of the $0.54 \mathrm{GO} / \mathrm{TC} 4$ composite indicated that GO agglomeration would occur in the case of higher GO contents in the composite, which, in turn, slightly decreased the density of the sintered composite.
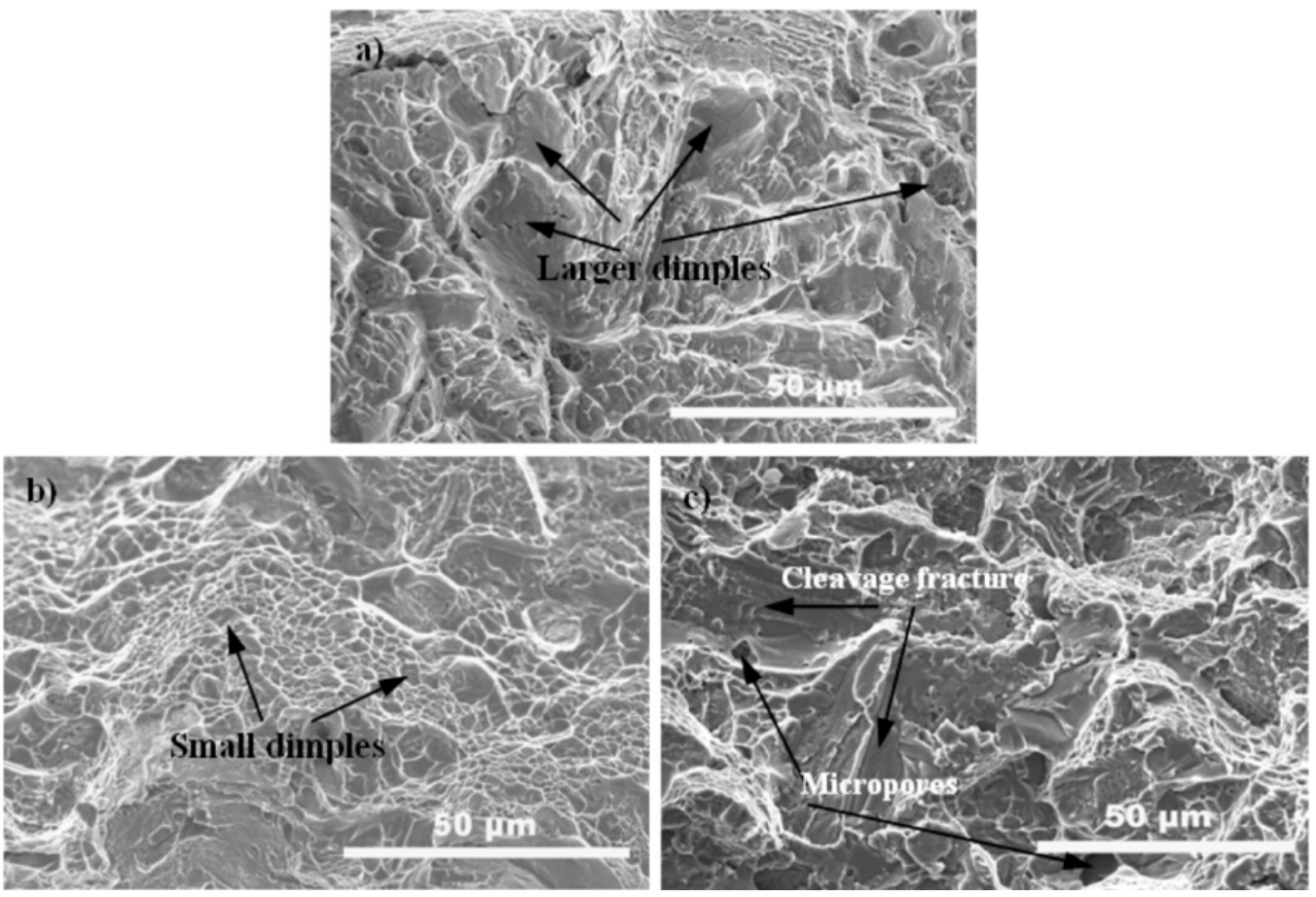

Figure 7. SEM images showing the tensile fracture surfaces of the monolithic TC4 sample (a), 0.27GO/TC4 composite (b), and 0.54GO/TC4 composite (c).

\section{Conclusions}

A graphene oxide nanosheet-reinforced Ti6Al4V (GO/TC4) composite was successfully fabricated using spark plasma sintering (SPS), in which the electrostatic self-assembly 
method was employed to homogeneously disperse GO in the TC4 powders. The main findings of this research can be summarized as follows:

- As compared with the typical Widmanstätten microstructure in the monolithic TC4 sample, the high residual tensile stress generated from the mismatch of coefficients of thermal expansion (CTE) between GO and TC4 was responsible for the presence of the typical basket-weave in the matrix microstructure of the composites. More importantly, an in situ-formed local $\mathrm{TiC}$ nanolayer and diffusion layer were identified at the GO-TC4 interface.

- In comparison with the TC4 sample, the 0.27GO/TC4 composite exhibited an improved strength (yield strength of $921.8 \mathrm{MPa}$ and ultimate tensile strength of $1040.1 \mathrm{MPa}$ ) and a similar elongation of $5.3 \%$, achieving a better balance between strength and ductility.

- The enhanced strength is closely related to the synergetic strengthening mechanisms such as Orowan strengthening, enhanced dislocation density strengthening, and load transfer, in which the improved interfacial bonding between the nanofiller and TC4 matrix due to the presence of a $\mathrm{TiC}$ nanolayer and diffusion layer at the interface makes load transfer greatly responsible for the enhanced strength of the composites.

Author Contributions: Conceptualization, methodology, writing—original draft preparation, writingreview and editing, project administration, funding acquisition, Y.C.; methodology, data curation, visualization, writing—original draft preparation, Y.S. (Ying Song); methodology, visualization, W.L.; methodology, data curation, Y.S. (Yufeng Sun); methodology, data curation, S.G. All authors have read and agreed to the published version of the manuscript.

Funding: This research was funded by the National Natural Science Foundation of China (51471113, 51275326).

Institutional Review Board Statement: Not applicable.

Informed Consent Statement: Not applicable.

Data Availability Statement: The data presented in this study are available o request from the corresponding author.

Acknowledgments: The authors would like acknowledge the financial support from the National Natural Science Foundation of China (51471113, 51275326).

Conflicts of Interest: The authors declare no conflict of interest.

\section{References}

1. Henriques, V.A.R.; de Campos, P.P.; Cairo, C.A.A.; Bressiani, J.C. Production of titanium alloys for advanced aerospace systems by powder metallurgy. Mater. Res. 2005, 8, 443-446. [CrossRef]

2. Hu, Y.; Cong, W.; Wang, X.; Li, Y.; Ning, F.; Wang, H. Laser deposition-additive manufacturing of TiB-Ti composites with novel three-dimensional quasi-continuous network microstructure: Effects on strengthening and toughening. Compos. B 2018, 133, 91-100. [CrossRef]

3. Hayat, M.D.; Singh, H.; He, Z.; Cao, P. Titanium metal matrix composites: An overview. Compos. A 2019, 121, 418-438. [CrossRef]

4. Abe, J.O.; Popoola, A.P.; Popoola, O.M. Consolidation of Ti6Al4V alloy and refractory nitride nanoparticles by spark plasma sintering method: Microstructure, mechanical, corrosion and oxidation characteristics. Mater. Sci. Eng. A 2020, $774,138920$. [CrossRef]

5. Abe, J.O.; Popoola, A.P.; Popoola, O.M. Influence of varied process parameters on the microstructure, densification and microhardness of spark plasma sintered Ti-6Al-4V/h-BN binary composite. In Proceedings of the 2019 6th International Conference on Mechanical, Materials and Manufacturing, Boston, MA, USA, 12-14 October 2019; IOP Conference Series: Materials Science and Engineering; IOP Publishing Ltd.: Bristol, UK, 2019; Volume 689, pp. 1-7.

6. Adebiyi, D.I.; Popoola, A.P. Mitigation of abrasive wear damage of Ti-6Al-4V by laser surface alloying. Mater. Des. 2015, 74, 67-75. [CrossRef]

7. Shang, C.Y.; Zhang, F.M.; Zhang, B.; Chen, F. Interface microstructure and strengthening mechanisms of multilayer graphene reinforced titanium alloy matrix composites with network architectures. Mater. Des. 2020, 196, 109119. [CrossRef]

8. Luo, S.D.; Li, Q.; Tian, J.; Wang, C.; Yan, M.; Schaffer, G.B. Self-assembled, aligned TiC nanoplatelet-reinforced titanium composites with outstanding compressive properties. Scr. Mater. 2013, 69, 29-32. [CrossRef] 
9. Yan, Z.; Feng, C.; Cai, Y.; Zheng, Y. Microstructure and mechanical properties of in-situ synthesized TiB whiskers reinforced titanium matrix composites by high-velocity compaction. Powder Technol. 2014, 267, 309-314. [CrossRef]

10. Li, S.; Kondoh, K.; Imai, H.; Chen, B.; Jia, L.; Umeda, J. Microstructure and mechanical properties of P/M titanium matrix composites reinforced by in-situ synthesized TiC-TiB. Mater. Sci. Eng. A 2015, 628, 75-83. [CrossRef]

11. Lacoste, E.; Arvieu, C.; Quenisset, J.M. Correlation between microstructures of SiCreinforced titanium matrix composite and liquid route processing parameters. J. Mater. Sci. 2015, 50, 5583-5592. [CrossRef]

12. Han, C.; Li, Y.C.; Liang, X.G.; Chen, L.P.; Zhao, N.; Zhu, X.K. Effect of composition and sintering temperature on mechanical properties of $\mathrm{ZrO}_{2}$ particulate-reinforced titanium-matrix composite. Trans. Nonferrous Metals Soc. China 2012, 22, 1855-1859. [CrossRef]

13. Jiao, Y.; Huang, L.J.; Wang, S.X.; Li, T.; An, Q.; Cui, X.P. Effects of first-scale $\mathrm{TiB}_{\mathrm{w}}$ on secondary-scale $\mathrm{Ti}_{5} \mathrm{Si}_{3}$ characteristics and mechanical properties of in-situ $\left(\mathrm{Ti}_{5} \mathrm{Si}_{3}+\mathrm{TiB}_{\mathrm{w}}\right) / \mathrm{Ti}$ Al4V composites. J. Alloys Compd. 2017, 704, 269-281. [CrossRef]

14. Tjong, S.C.; Mai, Y.W. Processing-structure-property aspects of particulate- and whisker-reinforced titanium matrix composites. Compos. Sci. Technol. 2008, 68, 583-601. [CrossRef]

15. Huang, L.J.; Geng, L.; Li, A.B.; Yang, K.F.; Peng, X.H. In situ TiBw/Ti-6Al-4V composites with novel reinforcement architecture fabricated by reaction hot pressing. Scr. Mater. 2009, 60, 996-999. [CrossRef]

16. Geim, A.K.; Novoselov, K.S. The rise of graphene. Nat. Mater. 2017, 6, 183-191. [CrossRef] [PubMed]

17. Balandin, A.A.; Ghosh, S.; Bao, W.; Calizo, I.; Teweldebrhan, D.; Miao, F.; Lau, C.N. Superior Thermal Conductivity of Single-Layer Graphene. Nano Lett. 2008, 8, 902-907. [CrossRef]

18. Zhu, Y.; Murali, S.; Cai, W.; Li, X.; Suk, J.W.; Potts, J.R.; Ruoffff, R.S. Graphene and Graphene Oxide: Synthesis, Properties, and Applications. Adv. Mater. 2010, 22, 3906-3924. [CrossRef]

19. Tjong, S.C. Recent progress in the development and properties of novel metal matrix composites reinforced with carbon and graphene nanosheets. Mater. Sci. Eng. R 2013, 74, 281-350. [CrossRef]

20. Zhang, H.P.; Cong, X.; Xiao, W.L.; Ameyama, K.; Ma, C.L. Enhanced mechanical properties of Al5083 alloy with graphene nanoplates prepared by ball milling and hot extrusion. Mater. Sci. Eng. A 2016, 658, 8-15. [CrossRef]

21. Vasanthakumar, K.; Ghosh, S.; Koundinya, N.T.B.N.; Ramaprabhu, S.; Bakshi, S.R. Synthesis and mechanical properties of TiCX and $\mathrm{Ti}(\mathrm{C}, \mathrm{N})$ reinforced titanium matrix in situ composites by reactive spark plasma sintering. Mater. Sci. Eng. A 2019, 759, 30-39. [CrossRef]

22. Xu, Z.S.; Shi, X.L.; Zhai, W.Z.; Yao, J.; Song, S.Y.; Zhang, Q.X. Preparation and tribological properties of TiAl matrix composites reinforced by multilayer graphene. Carbon 2014, 67, 168-177. [CrossRef]

23. Dong, L.L.; Xiao, B.; Liu, Y.; Li, Y.L.; Fu, Y.Q.; Zhao, Y.Q.; Zhang, Y.S. Sintering effect on microstructural evolution and mechanical properties of spark plasma sintered Ti matrix composites reinforced by reduced graphene oxide. Ceram. Int. 2018, 44, 17835-17844. [CrossRef]

24. Liu, J.; Wu, M.; Yang, Y.; Yang, G.; Yan, H.; Jiang, K. Preparation and mechanical performance of graphene platelet reinforced titanium composites for high temperature applications. J. Alloys Compd. 2018, 765, 1111-1118. [CrossRef]

25. Chen, H.; Mi, G.B.; Li, P.J.; Huang, X.; Cao, C.X. Microstructure and tensile properties of graphene-oxide-reinforced hightemperature titanium-alloy-matrix composites. Materials 2020, 13, 3358. [CrossRef] [PubMed]

26. Stankovich, S.; Dikin, D.A.; Dommett, G.H.B.; Kohlhaas, K.M.; Zimney, E.J.; Stach, E.A.; Piner, R.D.; Nguyen, S.T.; Ruoff, R.S Graphene-based composite materials. Nature 2006, 442, 282-286. [CrossRef] [PubMed]

27. Lin, D.; Liu, C.R.; Cheng, G.J. Single-layer graphene oxide reinforced metal matrix composites by laser sintering: Microstructure and mechanical property enhancement. Acta Mater. 2014, 80, 183-193. [CrossRef]

28. Song, Y.; Chen, Y.; Liu, W.W.; Li, W.L.; Wang, Y.G.; Liu, X.B. Microscopic mechanical properties of titanium composites containing multi-layer graphene nanofillers. Mater. Des. 2016, 109, 256-263. [CrossRef]

29. Huang, L.J.; Geng, L.; Xu, H.Y.; Peng, H.X. In situ TiC particles reinforced Ti6Al4V matrix composite with a network reinforcement architecture. Mater. Sci. Eng. A 2011, 528, 2859-2862. [CrossRef]

30. Huang, X.; Gao, Y.; Wang, Z.P.; Yi, Y.L.; Wang, Y.R. Microstructure, mechanical properties and strengthening mechanisms of in-situ prepared $\left(\mathrm{Ti}_{5} \mathrm{Si}_{3}+\mathrm{TiC}_{0.67}\right) / \mathrm{TC} 4$ composites. J. Alloys. Compd. 2019, 792, 907-917. [CrossRef]

31. Zhang, Y.; Chang, G.; Liu, S.; Tian, J.Q.; Wang, L.; Lu, W.B.; Qin, X.Y.; Sun, X.P. Microwave assisted, environmentally friendly, one pot preparation of $\mathrm{Pd}$ nanoparticles/graphene composites and their application in electrocatalytic oxidation of methanol. Catal. Sci. Technol. 2011, 1, 1636-1640. [CrossRef]

32. Murr, L.E.; Esquivel, E.V.; Quinones, S.A. Microstructures and mechanical properties of electron beam-rapid manufactured Ti-6Al-4V biomedical prototypes compared to wrought Ti-6Al-4V. Mater. Charact. 2009, 60, 96-105. [CrossRef]

33. Dong, L.L.; Lu, J.W.; Fu, Y.Q.; Hou, W.T.; Lin, Y.; Li, D.D.; Zhang, Y.S. Carbonaceous nanomaterial reinforced Ti-6Al-4V matrix composites: Properties, interfacial structures and strengthening mechanisms. Carbon 2020, 164, 272-286. [CrossRef]

34. De Barros, M.I.; Rats, D.; Vandenbulcke, L.; Farges, G. Influence of internal diffusion barriers on carbon diffusion in pure titanium and Ti6Al4V during diamond deposition. Diam. Relat. Mater. 1999, 8, 1022-1032. [CrossRef]

35. Li, J.; Zhang, X.; Geng, L. Effect of heat treatment on interfacial bonding and strengthening efficiency of graphene in GNP/Al composites. Compos. A 2019, 121, 487-498. [CrossRef]

36. Cao, C.; Daly, M.; Singh, C.V.; Sun, Y.; Filleter, T. High strength measurement of monolayer graphene oxide. Carbon 2015, 81, 497-504. [CrossRef] 
37. Asgharzadeh, H.; Eslami, S. Effect of reduced graphene oxide nanoplatelets content on the mechanical and electrical properties of copper matrix composite. J. Alloys Compd. 2019, 806, 553-565. [CrossRef]

38. Kim, W.J.; Lee, T.J.; Han, S.H. Multi-layer graphene/copper composites: Preparation using high-ratio differential speed rolling, microstructure and mechanical properties. Carbon 2014, 69, 55-65. [CrossRef]

39. Arsenault, R.J.; Shi, N. Dislocation generation du to differences between the coefficients of thermal expansion. Mater. Sci. Eng. 1986, 81, 175-187. [CrossRef] 